\title{
KOMUNIKASI SINGKAT : LAPORAN KEBERADAAN JAMUR BERACUN Podostroma cf. cornu-damae DARI LUAR BOGOR DI INDONESIA
}

\author{
Ivan Permana Putra \\ Divisi Mikologi, Departemen Biologi, Institut Pertanian Bogor \\ *corresponding author: ivanpermanaputra@apps.ipb.ac.id
}

\begin{abstract}
Podostroma cornu-damae in Indonesia was first reported by Boedijn in 1934 in Buitenzorg (Bogor), West Java. Since then, there have been no report of this macrofungi in Indonesia. In 2020, somel local people (the members of the Indonesian mushroom hunter community) shared the information about the occurence of this mushroom at the forests of Tamiang Layang (Central Kalimantan) and Sukabumi (West Java). Morphological identification based on macroscopic characteristics confirmed the identity of the macrofungi as Podostroma cf. cornu-damae and Podostroma sp.The brief descriptions is also provided in this paper. Observation using microscopic characters and or molecular approach is needed to be done to ensure the taxonomical position of the mushroom in the future research. This information add the inventory data on mushroom diversity in Indonesia.
\end{abstract}

Keywords: Inventory, Macrofungi, Indonesia, Podostroma cf. cornu-damae

\begin{abstract}
ABSTRAK
Podostroma cornu-damae di Indonesia pertama kali dilaporkan oleh Boedijn pada tahun 1934 di Buitenzorg (Bogor), Jawa Barat. Sejak saat itu, tidak ditemukan adanya laporan kembali mengenai jamur tersebut di Indonesia. Pada tahun 2020, beberapa masyarakat lokal yang tergabung dalam komunitas pemburu jamur Indonesia membagikan informasi mengenai keberadaan jamur tersebut dari Hutan Tamiang Layang (Kalimantan Tengah) dan Sukabumi (Jawa Barat). Identifikasi morfologi yang disertai deskripsi dan karakterisasi makroskopis mengkonfirmasi identitas jamur tersebut sebagai Podostroma cf. cornu-damae dan Podostroma sp. Observasi karakter mikroskopis dan atau pendekatan molekuler perlu dilakukan untuk memastikan hal tersebut pada penelitian selanjutnya. Informasi ini menambah data inventarisasi kekayaan ragam jamur di Indonesia.
\end{abstract}

Kata Kunci: Inventarisasi, Jamur, Indonesia, Podostroma cf. cornu-damae

\section{PENDAHULUAN}

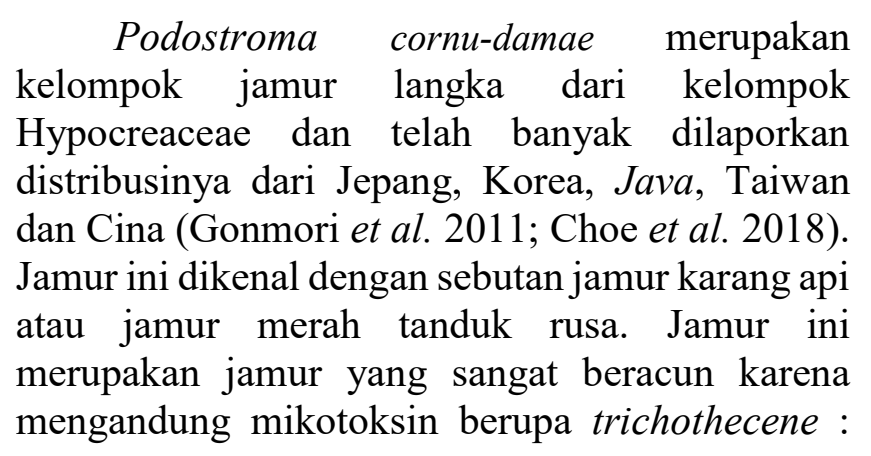

termasuk satratoxins, tratoxin, roridin, dan verucarin (Graeme, 2014; Lee et al. 2018) dan telah menyebabkan berbagai kasus keracunan hingga kematian. Sebagain besar jenis dari jamur ini awalnya dideskripsikan sebagai Hypocrea dan kemudian dipindahkan ke beberapa genus (Chamberlain et al. 2004) yakni menjadi Podocrea (sudah tidak digunakan), Podostroma, dan Trichoderma. Informasi 
terkini terkait penyesuaian tersebut mengikuti Mycobank dan Indexfungorum.

Di Indonesia, jamur ini pertama kali dipertelakan oleh Boedijn pada tahun 1934 dari Bogor, Jawa Barat. Setelah itu belum ditemukan lagi adanya laporan terkait jamur ini di Indonesia. Tulisan ini melengkapi laporan Putra dan Khafazallah (2020) dengan tambahan informasi awal berupa deskripsi guna observasi lebih lanjut mengenai keberadaan Podostroma di Kalimantan Tengah dan Jawa Barat.

\section{METODE}

Informasi keberadaan jamur diperoleh dari masyarakat lokal/ adat dari Kalimantan Barat dan penggiat jamur dari Jawa Barat. Deskripsi jamur dilakukan dengan menggunakan karakter makroskopik dengan merujuk pada Putra et al. (2018) dengan modifikasi. Tubuh buah jamur kemudian didokumentasikan dengan lengkap dan dilakukan validasi deskripsi informasi yang diperoleh. Parameter identifikasi makroskopik meliputi tempat tumbuh, cara tumbuh, bentuk tubuh buah, warna tubuh buah, bentuk, permukaan, dan tingkat kebasahan. Genus yang diperoleh kemudian divalidasi mendekati spesies terdekat secara taksonomi (confer/cf) dengan menggunakan berbagai referensi identifikasi diantaranya Largent (1973), Arora (1986), Chamberlain et al. (2004), dan Rokuya et al. (2011). Posisi taksonomi dan nama terbaru dari jamur yang ditemukan mengikuti ketentuan dari indexfungorum.

\section{HASIL DAN PEMBAHASAN}

Sebanyak 2 jenis jamur dideskripsikan pada tulisan ini. Keduanya teridentifikasi sebagai genus Podostroma. Salah satu dari jamur tersebut memiliki karakter Podostroma cf. cornu-damae. Berdasarkan indexfungorum, secara taksonomi genus ini berada pada posisi Hypocreaceae, Hypocreales,

Hypocreomycetidae, Sordariomycetes, Pezizomycotina, Ascomycota, Fungi. Berdasarkan data dari indexfungorum (http://www.indexfungorum.org/Names/Names.a sp; diakses pada 29 agustus 2020) hanya terdapat sebanyak 20 spesies, subspesies, dan varietas Podostroma dari seluruh dunia. Berikut merupakan deskripsi dari Podostroma pada tulisan ini.

\section{Podostroma cf. cornu-damae}

Jamur ini tumbuh secara berkelompok dalam jumlah terbatas di tanah dekat perakaran tumbuhan. Jamur ini ditemukan di Hutan Tamiang Layang, Kalimantan Tengah (KT). Tubuh buah jamur ini (stromata) sederhana, tumbuh dari basal yang sama (Gambar 1A;B), cabang pada bagian basal dengan ukuran yang seragam, stromata di bagian atas basal berbentuk silindris (Gambar 2C), mengerucut di bagian ujung, lurus atau bercabang dikotom (Gambar 2D). Warna stromata dominan jingga pada bagian basal hingga hampir ke ujung tubuh buah, namun pada bagian ujungnya berwarna jingga kemerahan. Permukaan tubuh buah dengan lekukan kecil hingga halus.

\section{Podostroma sp.}

Jamur ini tumbuh secara berkelompok dalam satu koloni di tanah dekat perakaran tumbuhan. Jamur ini ditemukan di Hutan Sukabumi, Jawa Barat. Stromata dari jamur ini sederhana, berbentuk silindris, tumbuh dari basal yang sama dengan posisi basal yang lebih dalam, bagian ujung dari tidak terlalu runcing namun rata (Gambar 2A). Tubuh buah tidak bercabang, permukaan dengan lekukan kecil hingga halus, berwarna jingga kemerahan dari bagian basal hingga sebelum bagian apikal. Bagian ujung berwarna kuning emas dengan sedikit getah (Gambar 2B). Jamur ini secara temporer dibedakan dengan jenis yang ditemukan di KT berdasarkan pola bercabangan basal dan apikal tubuh buah, warna stromata pada bagian basal dan apikal, pola ujung apikal, dan keberadaan getah pada bagian ujung tubuh buah yang tidak bercabang. Observasi lebih lanjut diperlukan untuk memastikan jenis dari jamur ini.

Podostroma merupakan salah satu kelompok dari filum Ascomycota yang memiliki tubuh buah berukuran makroskopik. Karena ukurannya yang besar, jamur ini seringkali dianggap sebagai Basidiomycota oleh penggiat jamur dan masyarakat awam. Berdasarkan 
indexfungorum, nama terkini dari Podostroma cornu-damae adalah Trichoderma cornu-damae. Jamur ini merupakan bagian dari kelompok Hypocreaceae dan dipisahkan dari genus lainnya berdasarkan bentuk stromata berupa stipitate (bertangkai) dengan bentuk tabung atau gada
(Chamberlain et al. 2004). Beberapa jenis dari Xylaria juga memiliki bentuk stromata yang sama namun tidak bercabang dan memiliki warna gelap jika dibandingkan dengan Podostroma.

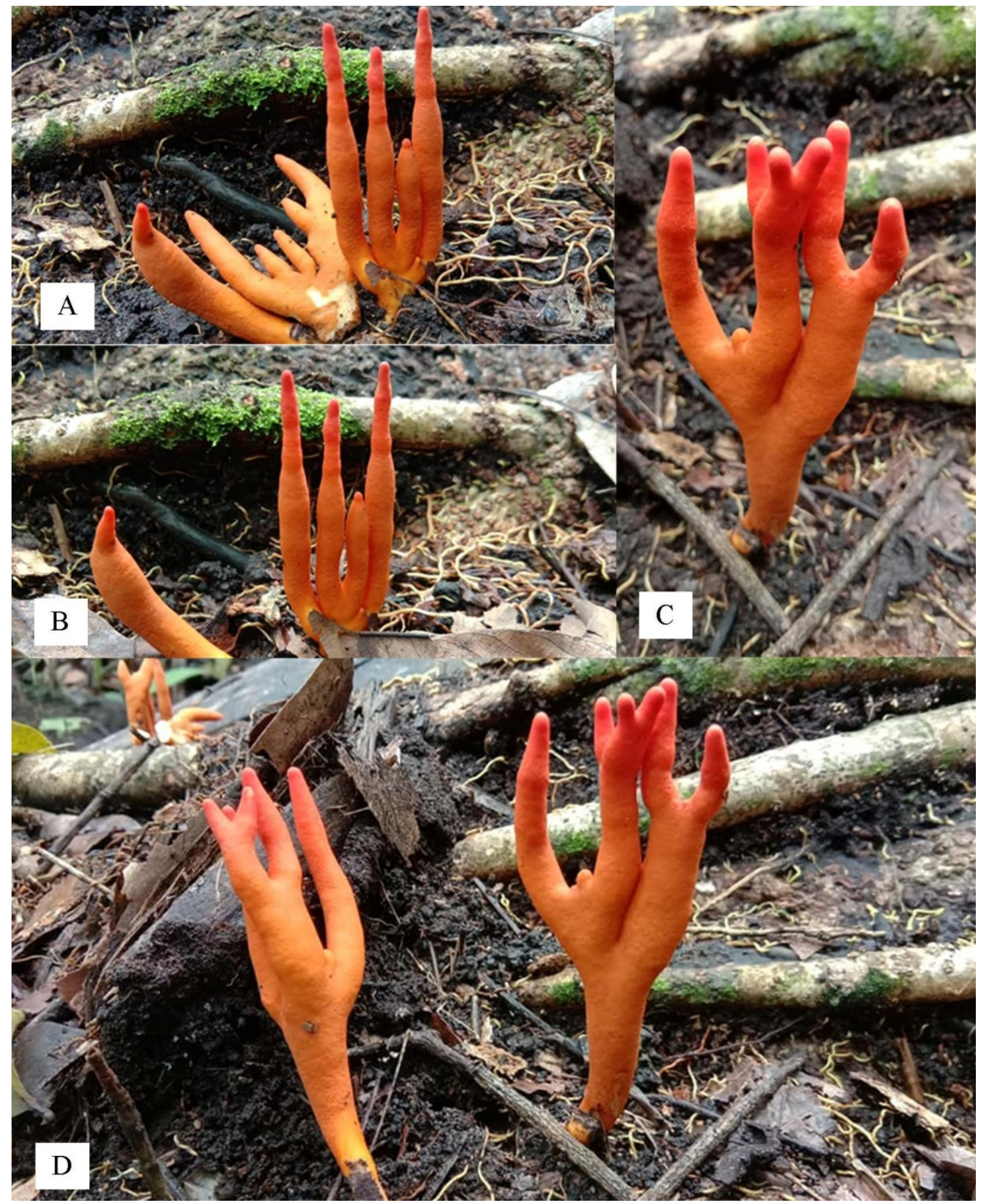

Podostroma cf. cornu-damae yang ditemukan di Kalimantan Tengah 


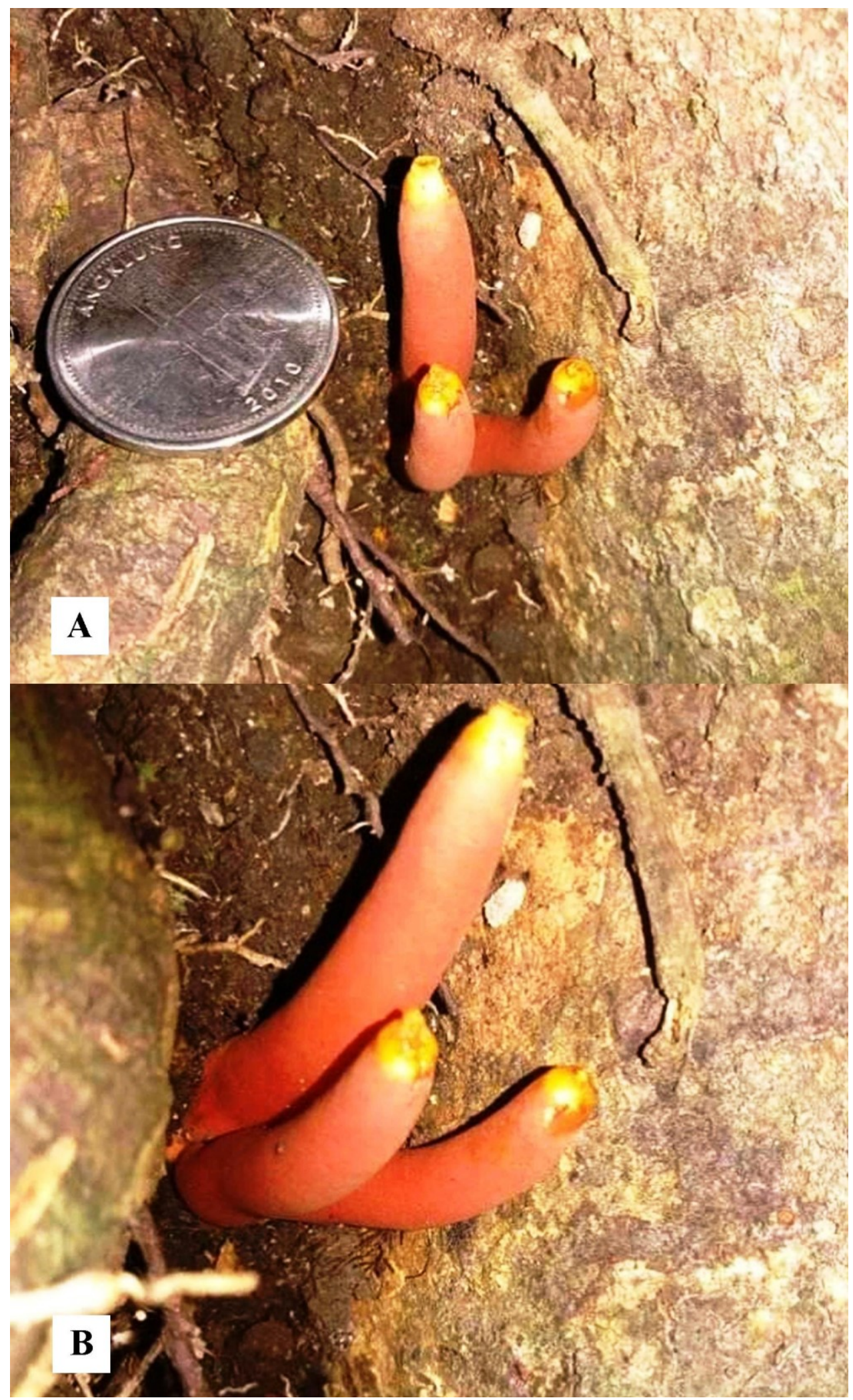

Podostroma sp.yang ditemukan di Sukabumi, Jawa Barat 
Podostroma beberapa kali dilaporkan terdistribusi di Jepang, Cina, Taiwan, Korea dan menjadi penyebab keracunan akibat kesalahan identifikasi oleh masyarakat awam. Hal ini dikarenakan fase primordia dari jamur ini sangat mirip dengan primordia Ganoderma lucidum dan Cordyceps militaris yang merupakan jamur obat (Gonmori et al. 2011; Graeme, 2014; Kim et al. 2016; Park et al. 2016; Choe et al. 2018).

Hingga saat ini diperkirakan terdapat sebanyak 100 jenis jamur yang telah diketahui menyebabkan keracunan pada manusia (Graeme, 2014). Informasi mengenai inventarisasi keberadaan jamur beracun dan termasuk kasus keracunan jamur di Indonesia sendiri belum pernah dilakukan sebelumnya (Putra, 2020). Hal ini juga kemungkinan disebabkan belum adanya checklist jenis jamur yang ada di Indonesia, jika dibandingkan dengan Malaysia (Li et al. 2008) dan Vietnam (Kiet, 2008). Upaya perekaman data dengan partisipasi dan kolaborasi dari penggiat jamur dan masyarakat adat di Indonesia merupakan salah satu cara untuk mengatasi hambatan geografis yang ada. Pencatatan Podostroma yang dilakukan pada tulisan ini menambah data jenis jamur di Indonesia. Deskripsi yang ada diharapkan menjadi media diseminasi yang dapat digunakan oleh masyarakat lokal sebagai upaya preventif tehadap keracunan jamur di Indonesia.

\section{PENUTUP}

Informasi mengenai keberadaan Podostroma cf. cornu-damae di Kalimantan Tengah dan Podostroma sp. di Jawa Barat ini perlu ditindaklanjuti lebih lanjut. Hal-hal yang perlu diperhatikan adalah terkait inventarisasi, identifikasi dengan karakter mikroskopik dan atau molekuler, serta preservasinya untuk melengkapi koleksi informasi keragaman jamur di Indonesia.

Penulis mengucapkan terimakasih kepada Hari Gloria Riwut Teka Murung dan Aswad Andriyanto yang telah membantu penulisan

\section{DAFTAR PUSTAKA}

Arora, D. 1986. Mushrooms Demystified. USA, Teen Speed Press.

Chamberlain, H. L., Rossman, A. Y., Stewart, E. L., \& Samuels, G. J. 2004. The stipitate species of Hypocrea (Hypocreales, Hypocreaceae) including Podostroma. Karstenia, 44(1-2), 1-24. http://dx.doi.org/10.29203/ka.2004.39.

Choe, S., In, S., Jeon, Y., Choi, H., \& Kim, S. 2018. Identification of trichothecenetype mycotoxins in toxic mushroom Podostroma cornu-damae and biological specimens from a fatal case by LC-QTOF/MS. Forensic Science International, 291, 234-244. http://dx.doi.org/10.1016/j.forsciint.201 $\underline{8.08 .043}$.

Gonmori, K., Fujita, H., Yokoyama, K., Watanabe, K., \& Suzuki, O. 2011. Mushroom toxins: a forensic toxicological review. Forensic Toxicology, 29(2), 85-94. http://dx.doi.org/10.1007/s11419-0110115-4.

Graeme, K. A. 2014. Mycetism: A Review of the Recent Literature. Journal of Medical Toxicology, 10(2), 173-189. http://dx.doi.org/10.1007/s13181-0130355-2.

Kiet, T.T. 2008. Preliminary checklist of macrofungi of Vietnam. Feddes Repertorium, 109(3-4),257-277. http://dx.doi.org/10.1002/fedr.1998109 $\underline{0309}$.

Kim, H. N., Do, H. H., Seo, J. S., \& Kim, H. Y. 2016. Two cases of incidental Podostroma cornu-damae poisoning. Clinical and Experimental Emergency Medicine, 3(3), 186-189. http://dx.doi.org/10.15441/ceem.15.028

Largent ,D.L. 1977. How to Identify Mushrooms to Genus I: Macroscopic Features. Eureka (CA), Mad River Press Inc. 
Lee, S.S, Horak, E., Alias,S. A., Zainuddin, N., Kin, T.,B., Nazura, Z. \& Jones, E.B.G.2008. Checklist of Literature on Malaysian Macrofungi. Forest Research Institute Malaysia (FRIM).

Lee, S. R., Seok, S., Ryoo, R., Choi, S. U., \& Kim, K. H. 2018. Macrocyclic Trichothecene Mycotoxins from a Deadly Poisonous Mushroom, Podostroma cornu-damae. Journal of Natural Products, 82(1), 122-128. http://dx.doi.org/10.1021/acs.jnatprod.8 $\underline{\mathrm{b} 00823}$.

Park, J., Min, J., Kim, H., Lee, S., Kang, J., \& An, J. 2016. Four Cases of Successful Treatment after Podostroma cornudamae Intoxication. Hong Kong Journal of Emergency Medicine, 23(1), 55-59.

http://dx.doi.org/10.1177/10249079160 2300107.

Putra, I.P., Sitompul, R., Chalisya, N. 2018. Ragam Dan Potensi Jamur Makro Asal Taman Wisata Mekarsari Jawa Barat. Al-Kauniyah: Jurnal Biologi, 11(2):133-150.

http://dx.doi.org/10.15408/kauniyah.v1 $1 \mathrm{i} 2.6729$

Putra, I.P., \& Hafazallah, K. 2020. Catatan Komunitas Pemburu Jamur Indonesia : Kolaborasi Lintas Profesi dan Generasi Mengenai Etnomikologi Jamur-Jamur Indonesia. Sukabumi : Haura Publishing.

Putra, I.P. 2020. Kasus keracunan Inocybe sp. di Indonesia. Prosiding Seminar Nasional Biologi Di Era Pandemi Covid 19. Jurusan Biologi, Fakultas Sains dan Teknologi, Universitas Islam Negeri (UIN) Alauddin Makassar.

Rokuya, I., Yoshio, O., Tsugia, H. 2011. Fungi of Japan. Japan, Yama-Kei Publishers. 